\title{
Teachers' Experiences of the Implementation of the Curriculum and Assessment Policy Statement (CAPS) in Three Primary Schools in KwaZulu Natal
}

MAHARAJH, Lokesh Ramnath | NKOSI, Thandi || MKHIZE, Mbekezeli Comfort

\section{Abstract}

T is article examined on teachers' experiences on the implementation of CAPS, using three primary schools in KwaZulu-Natal. This article employed the curriculum theory as an analytical framework. The aim of this article is to examine teacher's experiences of the implementation of the Curriculum and Assessment Policy Statement (CAPS). The article employed a qualitative research design to gather data. The data gathered through the use of semi-structured face to face interviews with teachers. The findings of the article reveal that there are many dynamics and possibilities relating to curriculum change in South Africa. The findings of the article further reveal that despite the challenges facing CAPS, South Africa's education system as a whole is plagued by challenges. The challenges are attributed to lack of resources and poorly trained teachers. The article concludes that understanding these dynamics depend, to a large extent, on paying attention to constraints and challenges influencing curriculum change. This article fills the knowledge-gap with reference to teacher's first-hand knowledge of CAPS and the challenges associated with it. The article thus recommends that appropriate resources should be made available in order to ensure efficient and effective implementation of curriculum implementation. It also recommends that a teacher: learner ratio of 1:30 should be practiced to ensure that teachers give special attention to each learner.

Keywords: CAPS, Curriculum, Change, Challenges, Resources, KwaZulu-Natal 


\section{Introduction}

Since the advent of democracy in 1994, South Africa has introduced a number of educational reforms such as Outcomes-Based Education (OBE), National Curriculum Statements (NCS) and Curriculum and Assessment Policy Statement (CAPS) (Jansen, 2008; Chisholm, 2005; Bantwini, 2010). Educational reforms were in response to inequalities and imbalances in the education system, which were created by apartheid government. In accordance with educational reforms, the OBE significantly changed the teaching methods, from teacher-centred to learner-centred. In this context, the implementation of the Curriculum and Assessment Policy Statement (CAPS) was an important step in achieving educational reforms especially between former resourced and under-resourced schools. CAPS typically brings about significant changes in the methods of assessments, time that learners have to spend in the classroom from grade R-12 and new teaching approaches. However, CAPS has been plagued by challenges. The teachers are often frustrated by curriculum changes owing to lack of clear technical expertise to carry out teaching responsibilities (Mdutshane, 2007). The teachers often lack the theoretical knowledge and familiarity with principles informing the implementation of curriculum change.

The entirety of curriculum changes since the new democratic era has been disastrous in South Africa (Maphalala, 2006). Indeed, while new changes emphasise learner-centred approach, the teachers are ill-equipped to carry out the tasks. Magano (2006:2) argues that changes in curriculum policy may lead to greater changes from the teachers in the way they teach learners and the way learners learn in the classroom. Complicating the implementation of CAPS has been the shortage of subject specialists to support teachers in primary schools during curriculum implementation and the shortage of teachers who specialise in mathematics and physical science (Portfolio Committee on Basic Education, 2012). A change in curriculum therefore necessitates a change of the function of the teacher (van der Nest, 2012:5).

However, very few studies have focused on the experiences of teachers concerning the implementation of the new curriculum. At global scale, such a focus is essential in order to sensitise the educational pundits and specialists about the ramifications and implications of policy development and implementation in transitional societies. Through the lenses of this article, crucial lessons can be learned by educational pundits around the world regarding the possible flaws that might arise in an erroneously implemented education policy. These flaws are also evident in education reforms around the world. This article 
Teachers' Experiences of the Implementation of (CAPS) in KwaZulu-Natal Pry Schools 373

responds to the dearth in scholarly debates by responding to the following key question. What are teachers' experiences of the implementation of CAPS in three primary schools? Correspondingly, the primary objective is to understand teachers' experiences in the implementation of CAPS in primary schools.

Very little meaningful research with first-hand knowledge of teachers has dealt with CAPS at any length. Against this backdrop, this article provides the ground-breaking analysis of the implementation of CAPS. The article holds that the experiences of teachers are critical in terms of formulating relevant policies aimed at improving any new curriculum. The article contributes to the body of knowledge by shedding light on existing debates involving the implementation of a new curriculum. The article helps shape policy choices and direction aimed at enhancing the quality of education. At a local scale, the article does not only serve as evidenced-based monitoring and evaluation tool but it informs future policy interventions in schools. At a global scale, the implementation of CAPS is squarely in sync with the educational challenges which are experienced by transitional governments.

The breakdown of the article is as follows. The article begins by revealing the research design employed in gathering data. It provides a definition of CAPS. It also provides the theoretical framework that was employed in analysing the variables of the study. It sheds light on the history, trends and contexts which are essential for curriculum change. It considers the rationale and the factors influencing curriculum change. The article ends off by presenting empirical data, conclusion and policy recommendations.

\section{Research Methodology}

This study employed a qualitative research design to collect data. The qualitative research design does not only allow the respondents to express themselves freely, but it also provides the researcher with the much needed flexibility when conducting interviews. This study was basically interpretive in nature. A case study approach was employed to collect data. Dunlap et al., (2009), define case study as an experiential inquiry that explores a contemporary phenomenon within its real life context. Three teachers from three primary schools were selected. The experience of three different schools with different performance levels helped our understanding of teachers' experiences in implementing CAPS in different ways.

The site of the study is three primary schools in the Pinetown district. These schools were selected because they fall under the same district. The totality of learners from these 
schools is largely from the same community - KwaNdengezi ward in Pinetown district. These schools are also on equal footing in terms of limited resources.

These three primary schools are the co-educational township schools offering only academic subjects and are attended by black learners. The schools are relatively disadvantaged. These schools do have an electricity supply, buildings are in good condition, but classes are overcrowded. A total of 55 learners were overcrowded into a single classroom. Learners speak isiZulu language. The local community consists of a few working-class families, and unemployment in the area is very high. 80-90\% of learners for each school qualify for fee exemption as parents are unable to pay the school fees.

The qualitative data collected through semi-structured face to face interviews was analysed using qualitative data analysis packages. Because the primary objective was to examine patterns, concepts and themes, the study employed content analysis method. Content analysis is defined as being what is said in a text, how it is said and how often it is said (Rugg \& Petre, 2006:157). Using this method has meant that data was categorised according to the emerged themes.

\section{Defining Curriculum and Assessment Policy Statement}

The Curriculum and Assessment Policy Statement (CAPS) is defined as a change to what is taught (a curriculum) and not how it is taught (teaching methods) (Department of Education (DoE), 2011). The CAPS is used as starting point for filling in gaps, reducing repetition and clarifying where necessary. Under CAPS, learning area has been changed into subject, and Learning Outcomes and Assessment Standards are omitted but are reworked into general aims of the South African curriculum and specific aims of each subject (DoE, 2011:7). In the past, Curriculum 2005 (C2005) and Revised National Curriculum Statement (RNCS) subjects were called learning areas. Under CAPS, they are traditionally referred to as subjects that are reduced from eight to six. Natural Science and Technology were combined to form one subject. Life Orientation and Arts and Culture were merged. The promotion requirements are different from the RNCS. Every subject in each grade has to have a single comprehensive and concise policy document that will provide details on what teachers need to teach and assess on a grade by grade and subject by subject basis. The curriculum review aims to lessen the administrative load on teachers - thereby ensuring that there is clear guidance and consistency for teachers when teaching. The curriculum is based on the content to be taught and learned (Thaanyane, 2010 and 
Teachers' Experiences of the Implementation of (CAPS) in KwaZulu-Natal Pry Schools 375

Marsh, 2009). It also includes the teaching and learning experiences undertaken to meet the intended learning objectives and the assessment of the learner about the knowledge of that curriculum.

\section{Theoretical Framework}

The curriculum theory is essential to understand the intricacies of curriculum changes. The theory offers expedient propositions and explanations. Curriculum theory is located within the broader field of curriculum studies (Pinar, 2012). Scholars within this field study the interdisciplinary relationships among curriculum, individual, and place (Pinar, 2012). This particular area of curriculum studies gained dominance throughout the 1970s and 1990s. Coined by Tyler around the 1950s and 1960s, the theory proposes a way of describing the educational philosophy of certain approaches to the development of curriculum. Although it gained dominance throughout the 1970s, it has shortcomings. Curriculum theory is not always compatible with the nature of human beings. Curriculum theory is sporadically used in a variety of common sense ways that have been accepted into general usage.

These shortcomings feature prominently in South African schools - where curriculum changes are often implemented without due regard of the environment. The implementation of OBE created confusion among teachers. The implementation of CAPS has also raised concerns. Despite these shortcomings, the South African experience confirms that curriculum theory is essential when dealing with curriculum changes. The theory helped the researchers to understand and analyse the experiences of teachers who are implementing CAPS.

\section{Historical background}

The South African education system experienced sudden changes in the curriculum (Prinsloo, 2007). These include the implementation of Outcomes Based Education (OBE), C2005, National Curriculum Statement (NCS), RNCS, and CAPS. Although there were motivational factors for curriculum reforms, numerous policy reforms were erroneous and fallible. Teachers were not properly trained to grapple with the changes. The teachers were not provided guidelines for handling basic principles of learning the assessment (Jansen and Taylor, 2003). The OBE was introduced largely to democratise education and eradicate inequality in the post-apartheid system (Jansen, 2008). Inequality created an ailing environment. In response, the $\mathrm{OBE}$ was introduced to ensure relevance and appropriateness. However, the environment did not allow for any radical changes. 
The C2005 was implemented to ensure redress in the education system. C2005 was a planned framework for curriculum innovation underpinned by redress, access, equity and development. It was destined to re-organise the curriculum which did not achieve its objectives. In a nutshell, C2005 was going to use an OBE teaching approach. Contrary to the OBE, C2005 believed that teachers were able to select the content and methods through which the learners have to achieve the outcomes.

Moreover, the NCS sought to ensure equal opportunity in a formerly divided system. The NCS responded to the problems experienced after C2005 (Jansen, 2009). Actually, the NCS evolved with grade 10-12 as major priority areas. The NCS gave expression to the values of democracy, human rights, social justice, equity, non-racism and Ubuntu (Badugela, 2012). The NCS focused on the outcomes and abandoned issues of content (Badugela, 2012).

Finally, CAPS, derived from RNCS, was introduced in response to the problems that plagued RNCS. Having been introduced in 2012, CAPS was intended to enlighten teachers about what they should teach in class and how they should assess learners. According to the Minister of Education, Angie Motshekga, CAPS was intended to ease the administration burden on teachers and to provide more clarity on what to be taught and assessed. This was necessary in order to provide a clear guidance and consistency in the manner in which things are done.

\section{Curriculum Changes in the International Context}

The curriculum changes in post-apartheid South Africa mirror the trends in the international context (Rogan and Grayson, 2003:1171). Global curriculum changes are motivated by attempts to prioritise curricula that focus on skills, application, and problemsolving (Adam, 2009). The changes in the global arena shape what is unfolding in the 'new' South Africa. The 1970s saw curriculum changes in many developed countries including the United States of America (USA). In USA, changes in science and mathematics were consistent with attempts to augment national security against the East. However, criticisms were levelled against educational reforms in the field of science (Bybee and Mclnerney, 1995). The educational reforms brought about serious concerns. In Turkey, the teachers were admired for great job in counteracting the difficulties associated with curriculum changes (Kirkgoz, 2008). Turkey provided a better understanding to the teachers about the curriculum through background training, sensitising them about lack of resources and 
Teachers' Experiences of the Implementation of (CAPS) in KwaZulu-Natal Pry Schools 377

classrooms overcrowding (Kirkgoz, 2008). The problems experienced by teachers after the implementation of CAPS reinforce and unequivocally confirm the on-going world-wide debates about erroneous educational reforms. It further confirms that policy-related problems in education are not distinctly South African. Of particular interest in this article is the fact that policies which do not consider the environment upon which they are implemented are most likely to fail.

\section{National context}

The rigidly centralised education provided a favourable climate for changes in South Africa (Frey \& Hameyer, 1988). South Africa is deficient and lagging behind compared with other developing countries including Zimbabwe in terms of the quality of education that is offered (Kiregyera 2010). The educational reforms were thus projected to rectify past racial inequalities and curb skill shortages in areas such as mathematics, science and technology (Bantwini, 2010:84). Post-apartheid South Africa has experienced a sequence of policies, regulations, and laws aimed at improving the state and quality of education more than any other transitional democracies (Jansen and Taylor, 2003:7). Central in the changes was the desire to address structural problems. From the first Minister of Education, Professor Sibusiso Bhengu, to the current Minister of Education, Angie Motshekga, the education system has been riddled with policy changes. However, curriculum changes were low during Professor Kader Asmal's term in office as the second minister of education (Jansen and Taylor, 2003).

Unlike the international context, the changes in curriculum occurred in two stages in South Africa (Jansen, 1998 and Chisholm, 2005). The first stage refreshed the syllabi by ensuring that racist and contentious language and outdated content were scrapped. The second stage introduced C2005 in March 1997. In particular, C2005 was premised upon ideals of democracy including harmony, wealth, non-racialism, and non-sexism. These values are enshrined in the South African constitution. Although South Africa has produced more educational policies than any other modern democracy; the policies have been characterised by 'gaps' (Jansen \& Taylor, 2003). These 'gaps' have amounted to a deficit of the education system in general. This deficiency in education is attributed to the lack of capacity, political will and resource shortages (Jansen and Taylor, 2003). 


\section{The Rationale behind Curriculum Change}

Curriculum change does not occur in a vacuum. Instead, "there are many broad influences that shape a curriculum, set its scope, and that provide a sense of coherence throughout the educational experience" (Kandiko \& Blackmore, 2012, p.1). The curriculum is largely shaped by the local context in which it occurs (Kandiko \& Blackmore, 2012). Globally, there is a tendency to privilege particular curriculum discourses informed by global and market pressures at the expense of institutional driving forces (Adam, 2009). This tendency neglects the role of agency, local and institutional discourses. The curriculum experiences significant pressure to transform from its 'insular', distant and abstract form to one that is more responsive to the direct needs of society (Adam, 2009). However, the needs of society tend to be at the heart of curriculum changes in science, mathematics, and modern foreign languages in the ascendency.

In addition, curriculum change could also be driven by economic, political, and social factors (Smith, 2001). Economically, Smith (2001) believes that constitutional adjustment programmes have had a negative impact on many emerging economies. Politically, Smith (2001) argues that a new government tends to bring in new ideology. Finally, it could be a mixture of economic and political factors. In South Africa the curriculum changes have not immensely improved the quality of education (Jansen \& Taylor, 2003). In many parts of the world, curriculum changes have focused on improving application and problemsolving skills while in South Africa changes have been about ensuring education that is learner-centred. The following section deals with what influences curriculum implementation.

\section{Factors Influencing Curriculum Implementation in South Africa}

First, the shortage of resources is the critical problem influencing curriculum implementation. The inadequate facilities including classrooms, laboratories, libraries and playing grounds can affect the implementation of the new curriculum (Jansen and Taylor, 2003).

Van der Nest (2012:36) concurs and classified educational resources into three categories namely: human resources, cultural resources and material resources. First, human resources include the teachers themselves and the pedagogic content knowledge that they embody. Second, cultural resources include language, time, and other culturally available tools or concepts. Third, material resources are technologies, curricular 
Teachers' Experiences of the Implementation of (CAPS) in KwaZulu-Natal Pry Schools 379

documents, and textbooks that may be incorporated into the teaching and learning process. Material resources are lacking in many South African mathematics classrooms. Resources impact negatively on untrained teachers.

The issue of untrained teachers is by far the greatest challenge. Educators need to be trained how to develop their own resource materials which is time-consuming; construction of classroom resources; profile and track each learner; discuss projects with groups of learners and for cooperation between teachers (Badugela, 2012). To this end, C2005 was a challenge for many South African teachers who had inadequate knowledge, skills and competences (Jansen \& Christie, 2005).

The implementation of curriculum change is also plagued by financial constraints. The government introduced the concept of no-fee schools in order to accommodate parents who are financially needy. The funds are needed in schools to purchase learning and teaching support materials (LTSM) (Badugela, 2012). Many economic support systems for schools exist such as Section 20 schools (those schools which do not receive the full budget amount from the DoE for stationery and textbooks) and Section 21 schools (those schools which received the full budget amount from the DoE for stationery and textbooks) (Badugela, 2012). The financial constraints impact badly on the implementation of the curriculum in South Africa.

Parental involvement affects the implementation of curriculum change by improving the academic achievement of learners (Sclafani, 2004). However, the educators do not attract adequate support from the parents (DeCastro-Ambrosetti \& Cho, 2005). The parents believe that it is not their role to assist children with their school work (DeCastroAmbrosetti \& Cho, 2005). The hindrance is that parents are ill-informed regarding curriculum implementation. As a consequence, they are unable to help the children. In South Africa, the involvement of parents in children's education is minimal because parents have problems of their own (Fullan, 2007). The parents lack the knowledge to become involved.

\section{Facilitating Curriculum Implementation in South Africa}

Fullan (1993) explains that changing from one curriculum to another on a national scale is extremely difficult. It cannot be achieved without the significant integration of teachers in the process (Taole, 2013). The teachers' views on curriculum innovation and implementation process are imperative in ensuring success (Taole, 2013). The teachers play 
an integral part in the implementation of the curriculum (Nunalall, 2012). It is imperative that teachers' conception and thinking about curriculum review be investigated. These determine their acceptance and rejection of revision. If teachers' viewpoints are not incorporated in curriculum implementation, it becomes a mismatch between the official curriculum prescribed by the curriculum developers and the actual curriculum taught by teachers in their classrooms (Cuban, 1993).

The implementation problems include multiple interpretations of the curriculum and workload. Such interpretations often become a challenge that teachers face in the implementation of any new curriculum (Smit 2001; Chisholm 2005; Pudi 2006, Taole 2013).

It is important to provide training and support to teachers, school management teams and parents in order to achieve effective curriculum implementation (Dunlap, Lovannone, Wilson, Kincaid \& Strain, 2009). Subject specialists need to support teachers and undertake a monitoring process in order to comprehend what is happening in classroom situations. There must be a close connection between school improvement work and initial teacher training (Dunlap et al, 2009). Teachers must be encouraged to form clusters (intermediate phase cluster) because by doing so they can share ideas and experiences regarding the curriculum implementation by reviewing their teaching style, teaching resources and school functions (Mdutshane, 2006). The teacher training and teacher support play an essential role on how to implement the curriculum by influencing teachers' understandings and their classroom practices (Kirkgoz, 2008:2). Skills and training should be available to ensure the requirements of the new curriculum are met (Fullan, 1993).

\section{Research Findings}

\section{Experiences of Teachers on Curriculum Implementation in South Africa}

While focusing on the experiences of three teachers from three primary schools, the study reveals that the implementation of CAPS has been elusive. In theory, the findings suggest that CAPS is a viable policy, but the implementation is erroneous. The CAPS is fallible because of lack of favourable conditions including resources, suitably qualified and experienced teachers, and the support from the DoE. For example, teachers are not adequately trained for implementing CAPS.

The CAPS is also a top-down approach. The participants felt that they were not adequately consulted before CAPS was implemented. The lack of consultation is a 
Teachers' Experiences of the Implementation of (CAPS) in KwaZulu-Natal Pry Schools 381

contributing factor to the failure of CAPS. The classroom sizes also compound the problem as teachers were struggling to contain big classes.

\section{Teachers' knowledge of CAPS}

The researchers asked teachers questions about the previous curriculum policies and teachers' knowledge of those policies in order to make sense of their understanding of CAPS. The participants understood the previous policies.

The participants were also asked if they identified any differences between C2005, NCS and RNCS. Participant 1 responded that: C2005 was not practical. Several studies concur due to too much emphasis on the outcomes without stating what should go into the system for the outcomes to be achieved, poor training of teachers and shortages of personnel and resources to implement and support C2005 (Cross, Mungadi, \& Rouhani, 2010).

Participant 2 has an incomplete or misplaced idea of CAPS since her response to the differences between C2005, NCS and RNCS was: In fact, the content is the same the only difference is that the focus in CAPS is on content not on learning areas.

Although the three teachers knew the previous curriculum policies in South Africa, they did not know why there are different curriculum policies at different times. However, Sahlberg (2007) holds that one of the habits of driving a successful curriculum change is to make sense of why a new curriculum is necessary. The good understanding of change and clear formation of curriculum are necessary conditions for improved implementation of CAPS (Sahlberg, 2007).

The participants indicate that although CAPS is a good policy, it is a top down policy because there has not been any follow up after the implementation of CAPS at the classroom level. While curriculum implementers, teachers are not involved in curriculum planning. They are only involved at the implementation phase. DeCastro-Ambrosetti \& Cho (2005) hold that there is a need for teachers to be involved in curriculum planning because lack of teacher participation can lead to lack of ownership. The participants also indicated that the DoE provides teachers with policy documents which guide them as to how they can prepare their lessons. The aim of CAPS is to provide clarity of the requirements of what is to be taught and learnt on a term-by-term basis (DoE, 2011). This kind of system does not encourage critical thinking amongst teachers who are frequently managed by the policy document (Nunalall, 2012:15). 
The participants said that there is a task team of people who work for the DoE. The teachers are not involved in the policy formulation. Policy formulation in South Africa is conceived as a rational and firm process in which policy making is seen as different from policy implementation (Govender, 2008). Policy formulation in the school sector has become the sphere of government policy makers and policy experts, while policy implementation was seen as the responsibility of teachers (Govender, 2008). The knowledge and expertise of teachers was not considered in spite of their location in the policy cycle (Nunalall, 2012). The teachers' experiences are marginalised in the policy field (Nunalall, 2012).

The new curriculum was formulated in order to rectify the challenges that were caused by previous policies. The formulation of CAPS was to discover challenges and pressure points that had a negative impact on the quality of teaching in schools. And, possibly come up with mechanisms that could address those challenges (DoE, 2011).

CAPS concerns were: complaints about the implementation of NCS, teachers who were overburdened with administration, different interpretations of the curriculum requirements and underperformance of learners (Department of Basic Education, 2009). CAPS policy provided information for every subject in each grade about what content teachers need to teach and assess (Pinnock, 2011). The principles of CAPS were to encourage an active and critical approach to learning, rather than rote and uncritical learning of given truths (Pinnock, 2011).

\section{Training}

All three participants agreed that they did receive training, but they indicated that the training received was insufficient for them as curriculum implementers. They also expressed concern that subject advisors were unclear about CAPS as a new curriculum which made it difficult for subject advisors to assist teachers. The teachers need to be adequately trained. The inadequate training of teachers and the lack of resources make it complicated for teachers to learn what is expected from them (Badugela, 2012).

The participants further stated that due to insufficient training received, the teachers are not equipped with necessary skills. The teachers were not adequately equipped with required skills. Teachers need more training in order to be equipped to implement CAPS. Typically, teacher training does not provide teachers for the reality of the classroom (Fullan, 1991:118). The lack of appropriate resources diminishes the potential of sound 
Teachers' Experiences of the Implementation of (CAPS) in KwaZulu-Natal Pry Schools 383

implementation in the classrooms (Smith, 2001). Nunalall (2012) cautions that formulation of policy after policy may lead teachers to develop a negative attitude towards teaching. The teachers need to be provided with proper skills and knowledge in order to implement the new curriculum efficiently (Mncube, Thaanyane \& Mabunda, 2013:26).

Frequently, the participants also stated that the subject advisors who conducted those training workshops were not adequately trained about the new curriculum implementation and do not visit them. The teachers think that it is the responsibility of departmental officials to train teachers.

The researchers asked the participants what support, if any they receive from the School Management Team (SMT) in the implementation of the CAPS policy.

Participant 1: They moderate our work and help us to improve.

Participant 2: Not at the moment because they are not yet trained on CAPS.

Participant 3: Our SMT does organise some internal workshop where those teachers who attended the workshop cascade the information to other teachers. And they provide us with materials (LTSM).

The responses indicate that SMT does provide them with the necessary support needed, even though they are not trained for CAPS. Once the new curriculum is introduced, it becomes the responsibility of the district officials to train the SMT and teachers to experience a form of mind shift (Smith and Andrews, 1989). The SMT should provide the teachers with the necessary resources in order to achieve the school's academic goal (Smith and Andrews, 1989). The SMT should supervise curriculum planning in the school and ensure that teaching and learning time is used efficiently (Mason, 2004).

\section{Resources}

The inadequate resources limit policy implementation (Cheng and Chueng, 1995:17). If the resource requirements and their use are not planned correctly, they lead to difficulties in implementing the new curriculum. The important resources relevant to educational policy are human resources, equipment and facilities, space and monetary resources (Rembe, 2006). These resources facilitate the implementation. Curriculum implementation depends on availability of resources.

The participants responded that resources are available but are not enough. Participants also stated that the DoE provides them with the policy documents which serve as a guide for what to teach, how to teach that particular topic according to terms and 
they also get workbooks. They also indicated that the policy documents provide them with time allocation per learning area. However, the policy documents that were provided to them were insufficient because each school only received two copies of policy documents for forty teachers in a school. The textbooks were also not enough for learners which resulted in the sharing of books. Shortage of teachers in schools is also a problem. Teachers ended up teaching more than two grades and more than two subjects.

The participants stated that overcrowded classrooms, lack of laboratories and libraries make it difficult to implement CAPS effectively. In their view, it is the responsibility of the DoE to ensure that resources are distributed properly.

Sufficient facilities such as classrooms, halls, libraries, laboratories and playing fields serve as the main elements in implementing the curriculum successfully (Van der Nest, 2012). The government agencies are also aware of the difficulties of implementing CAPS and allocating resources to clarify standards of practice (Fullan, 2007:100).

\section{Conclusion and Policy Recommendations}

The curriculum reforms were needed in South Africa given the fractured nature of the education system. The inequities ranging from uneven resource allocation to lack of uniformity in the quality of education have hampered progress. The changes in the curricula are mainly carried out with a view of ensuring equality, justice, and fairness in South Africa's education system.

While the international experience has had similar experiences regarding curriculum changes, it is problematic in South Africa. The implementation of CAPS has had challenges in schools. Currently, the implementation of CAPS is a difficult task. The literature and the data gathered through the interviews have attested to this enormous difficulty.

Proper training of teachers, ongoing support from the DoE and the provision of resources is essential in ensuring smooth curriculum implementation. Subject advisors need to lead the training by facilitating regular workshops. Not only are teachers expected to work tirelessly, but the parents are required to participate actively in the education of their children. The article argues that curriculum change in South Africa is a dynamic and challenging task. All stakeholders must participate equally.

There are gaps that need further research. For instance, it emerged that the provision of Learning and Teaching Support Material needs to be strengthened, and augmented in order to improve the implementation of CAPS. The LTSM needs to be examined in order 
Teachers' Experiences of the Implementation of (CAPS) in KwaZulu-Natal Pry Schools 385

to determine its efficiency in the implementation of CAPS. Infrastructure needs to be improved to overcome overcrowded classrooms.

The article recommends that CAPS needs to be implemented in order to redress the imbalances of the past. Using literature and empirical data, the following future trends are noted: a teacher: learner ratio of 1:30 must be practiced to ensure that teachers give special attention to each learner. Full support from the subject advisors is needed. Necessary resources must be provided in order to ensure effective curriculum implementation. The DoE needs to prioritise learning resources for schools and educator training. They can engage all stakeholders including School Governing Bodies (SGBs) and trade unions. Curriculum developers need to communicate with teachers to ensure better understanding of curriculum implementation.

\section{List of References}

- Adam, F 2009, 'Curriculum reform in higher education: A humanities case study', Doctoral Thesis. Johannesburg: University of the Witwatersrand.

- Badugela, TM 2012, 'Problems facing educators in implementing the national curriculum statement: the case study of Tshifhena Secondary school', Master of Education dissertation. Pretoria: University of South Africa.

- Bantwini BD 2010. How teachers perceive the new curriculum reform: Lessons from a school district in the Eastern Cape Province, South Africa. International Journal of Educational Development, 30(1):83-90.

- Bybee RW \& Mclnerney JD 1995. Redesigning the science Curriculum: A report on the implications of standards and benchmarks for science education.

- Cheong Cheng Y \& Ming Cheung W 1995. A framework for the analysis of educational policies. International Journal of Educational Management, 9(6):10-21.

- Chisholm L 2005. The politics of curriculum review and revision in South Africa in regional context. Compare, 35(1):79-101.

- Cross M, Mungadi R \& Rouhani S 2010. From policy to practice: Curriculum reform in South African education. Comparative Education, 38(2):171-187. 
- Cuban L 1993. How teachers taught: Constancy and change in American classrooms, 18901990. Teachers College Press.

- DeCastro-Ambrosetti D \& Cho G 2005. Do parents value education? Teachers' perceptions of minority parents. Multicultural Education, 13(2):44-46.

- Department of Basic Education 2009. Report of the task team for the review of the implementation of the National Curriculum Statement. Pretoria: Government

- Department of Education 2011. National Curriculum Statement Grades R-12. Available at http://www.education.gov.za. Accessed 11 September 2013.

- Dunlap G, lovannone R, Wilson K J, Kincaid DK \& Strain P 2009. Prevent-teach-reinforce: A standardized model of school-based behavioral intervention. Journal of Positive Behavior Interventions.

- Frey K \& Hameyer U 1988. Responses to austerity: European experiences from higher education and school improvement in the 1980s. International Review of Education, 34(3):371-378.

- Fullan MG 1991. The new meaning of educational change. London: Cassell.

- Fullan MG 1992. The new meaning of educational change (2nd ed). London. Cassel.

- Fullan MG 1993. Change forces. Probing the depths of educational reform. London: Falmer press.

- Fullan MG 2001. Leading in a culture of change. San Francisco: Jossey-Bass.

- Fullan MG 2007. The new meaning of educational change (4th ed). London

- Govender LV 2008. Teachers' participation in policy making: The case of the South African Schools Act. Doctoral dissertation. Johannesburg, South Africa. University of the Witwatersrand

- Jansen J \& Christie P (eds.) 1999. Changing curriculum: Studies on outcomes-based education in South Africa. Kenwyn: Juta \& Co.

- Jansen J 2008. Curriculum reform in South Africa: a critical analysis of outcomesbased education. Cambridge Journal of Education, 28:321-331.

- Jansen J \& Taylor N 2003. Educational change in South Africa 1994-2003: Case studies in large-scale education reform.

- Kandiko CB \& Blackmore P 2012. Curriculum organisation and outcomes. Strategic Curriculum Change: Global Trends, 43. 
- Kiregyera B 2010. The evidence gap and its impact on public policy and decision-making in developing countries. International Association of Statistical Education. ICOTS8. Kampala, Uganda.

- Kirkgoz Y 2008. A case study of teachers" implementation of curriculum innovation in English language teaching in Turkish primary school education. Teaching and Teacher Education, 24:1859-1875.

- Magano L 2009. How Natural Sciences teachers plan and enact their lessons in outcomesbased Education. Med dissertation. Pretoria: University of Pretoria.

- Maphalala MC 2006. Educators' experiences in implementing the revised national curriculum statement in the Get Band. Doctoral dissertation.

- Marsh C 2000. Perspectives: Key concepts for understanding curriculum. London, Falmer Press.

- Mason T 2004. Curriculum 2005. Revised National Curriculum Statement: Intermediate Phase. School Management Teams. Johannesburg: Wits.

- Mdutshane VN 2006. An investigation into implementation of Curriculum 2005. In Mncube V, Thaanyane M \& Mabunda P 2013. Chronicling teachers' experiences in the teaching of Business Education in three secondary schools in Lesotho. Anthropologist, 15(1): 67-78.

- Nunalall S 2012. The effect of continuous curriculum policy changes on the Professional lives of foundation phase in post-apartheid South Africa. MEd dissertation. Durban: University of KwaZulu-Natal.

- $\quad$ Pinar WF. 2012. What is curriculum theory? Routledge.

- Pinnock AJE 2011. A practical guide to implementing CAPS: A toolkit for teachers, school managers and education officials to use to assist in managing the implementation of a new curriculum. NAPTOSA.

- Prinsloo E 2007. Implementation of life orientation programmes in the new curriculum in South African schools: perceptions of principals and life orientation teachers. South African Journal of Education, 27(1):155-170.

- Pudi TI 2002. Teacher attitudes towards the implementation of the learning area Technology. University of South Africa.

- Rembe SW 2006. The politics of transformation in South Africa: an evaluation of education policies and their implementation with particular reference to the Eastern Cape Province. Doctoral dissertation. Grahamstown: Rhodes University. 
- Rogan MJ \& Grayson DJ 2003. Towards a theory of curriculum implementation with particular references to science education in developing countries. International Journal of Science Education. 25(10):1171-1204

- $\quad$ Rugg G \& Petre M 2006. A gentle guide to research methods. McGraw-Hill International.

- Sahlberg P 2007. Education policies for raising student learning: The Finnish approach. Journal of Education Policy, 22(2):147-171.

- Smith B 2001. How primary school teachers experience education policy change in South Africa? Perspectives in Education. 19(3). Smith WF \& Andrews RL 1989. Instructional leadership: How principals make a difference. Publications, Association for Supervision and Curriculum Development, 125 N. West Street, Alexandria, VA 22314.

- Taole MJ 2013. Teachers' conceptions of the curriculum. Review Process, 5(1):39

- Thaanyane ME 2010. Teachers' experiences of implementing Business Education in three Secondary Schools in Maseru district. Med dissertation. Durban: University of KwaZulu-Natal.

- Van der Nest A 2012. Teacher mentorship as professional development: Experiences of Mpumalanga primary school. Med dissertation. Durban: University of South Africa.

- Wilson S 1979. Explorations of the usefulness of case study evaluations. Evaluation Review 3(3):446-459.

\section{AUTHORS' CONTACT:}

MAHARAJH, Lokesh $\mathbf{R}$. School of Education University of KwaZulu-Natal Email: maharajhlr@ukzn.ac.za

\section{NKOSI, Thand}

Senior Education Specialist, Examination and Assessment Section, KwaZulu-Natal Email:
Mkhize, Mbekelezi C.

Researcher, Centre for Military

Studies (CEMIS)

Stellenbosch University

Email:

comfortm@ma2.sun.ac.za 